\title{
Formation of the Professional Competence of a student within the framework of the problem-oriented approach to training
}

\author{
E.V. Politsinskaya ${ }^{1}$, A.V. Sushko ${ }^{1}$, I.A. Semerenko ${ }^{1}$ \\ ${ }^{1}$ Tomsk Polytechnic University, Yurga Institute of Technology, Kemerovo Oblast, Yurga, 652050, Russia
}

\begin{abstract}
In the paper the authors consider the personality trait «creativity» as a potential opportunity of every person and as his/her need for being a unique personality. The authors suggest applying the problem-oriented approach to training and interactive training methods in the educational process of the higher education institution as their implementation allows not only encouraging students' thinking but also forming the creative constituent important for further professional activities and promoting solid career achievements.
\end{abstract}

\section{Introduction}

Social and economic changes affecting all aspects of human life have also significantly affected the system of education in the Russian Federation creating real opportunities for its modernization [13]. Labor market needs are the basic factor of education reform. Modern society needs an educated, entrepreneurial, ambitious worker capable of making important decisions independently in the situation of choice, realizing possible consequences, possessing creativity, communicativeness and mobility. As matters stand, formation of creative abilities of every person who ensures development of society, culture, science and production must become one of the main aims of modern higher professional education [3]. The Program of modernization of higher education of the Russian Federation sets the task of developing creative educational environment where individual characteristics of the students can be manifested to the best advantage.

\section{Materials and methods}

The universal general theory of creativity does not exist. Creativity has been analyzed by scientists for hundreds years. The term "creativity" in translation from Latin (creatio) means "creation". "Creativity" is a process of creative activity of a person. This activity is resultants from a new innovative product. Creativity is manifestation of the creator. The creator is the person who induces creative activity. The creator is responsible for the product she/he has created. The most well-known researchers of "creativity" are J. Guilford (1953) and E. Torrance (1988). Other authors claim that there are three aspects of creativity: person, process and product (N.Aderson (1990), T. Amabile (1998), E.Barron (1981), R.Woodman (1993), N.King (1990), etc.).

The interest in the problem of "creativity" appeared in the USA in the middle of the last century. The progressive scientists who made a significant contribution into the conception of creativity are J. Guilford and E.P. Torrance [6].

The authors associate the concept of "creativity" with having and introducing some idea aimed at creating a material product. The authors mark the important role of the analysis of the actor performance when realizing the idea. In his work S.L. Rubinstein emphasizes the necessity of paying attention to the personal aspects of creativity. According to him "creativity" is the process of developing something new and important and at the same time - of something original, which has the "imprint" of creative personality. S.L. Rubinstein stated that every created unique thing depends upon creator's personality [11].The conception developed by American psychologist Joy Paul Guilford in the $20^{\text {th }}$ century enabled a tremendous upgrowth of research and development in the field of creativity all over the world [6]. The cubiform model of the structure of the intellect developed by J. Guilford supposed development of separate creative abilities of a person, not development of general personal intellect. So, if a child demonstrates passion for knowledge in the field of physicomathematical sciences this knowledge should be developed by the teachers without trying to develop abilities in the field of, say, music. According to J. Guilford every person is talented in his/her own way. It is only important to recognize these abilities in due time and develop them. 
Further development of J. Guilford's ideas was done by E.P. Torrance. Torrance worked out his own method of teaching and guiding work aimed at development of children's creative abilities.

According to Torrance "creativity" is human ability for increased sensitivity to the problems, disharmony, gaps and misunderstanding of obtained knowledge, etc. In his works E.P. Torrance wrote that a creative act comprises:

- perception of the problem;

- searching for solution when the problem appears;

- statement of hypotheses, testing and modification of hypotheses;

- introduction and generation of results [6].

Torrance was able to view "creativity" generally, as the process of problem exploration, search for possible solutions, presentation of hypotheses, testing and evaluation, and reporting the results to others. He added that this process includes original ideas, other points of view, form destruction, combining ideas or presentation of new associations between the ideas. Although Torrance's definition of "creativity" was classical, it was subjected to criticism several years later and is considered outdated to a great extent.

Thus, creativity is a continuous process of social and cultural society. Creativity is a driving force which contributes to the positive self-rating of an individual in the society. Creativity is the process which leads to production of some object of "admiration".

Barron F. defined creativity as the creative product received by the creative person as result of a creative process. However this formulation omits aspect of creativity which even more often gained popularity in the field of research of creativity: creative environment. Thus, Barron's statement can be reformulated as follows: the creative product received by the way of the creative person is involved in a creative process in the creative environment [7].

Model 4-Ps offered by M. Rodes provides a more detailed structure for understanding of creativity [8]. The model postulates four concrete prospects of creativity, which were an object of research, namely creative processes, creative persons, creative products, and the creative environment. This model is mentioned by many researchers (Brown, Harinton, Stikhre and Sundgren, etc.) [9].

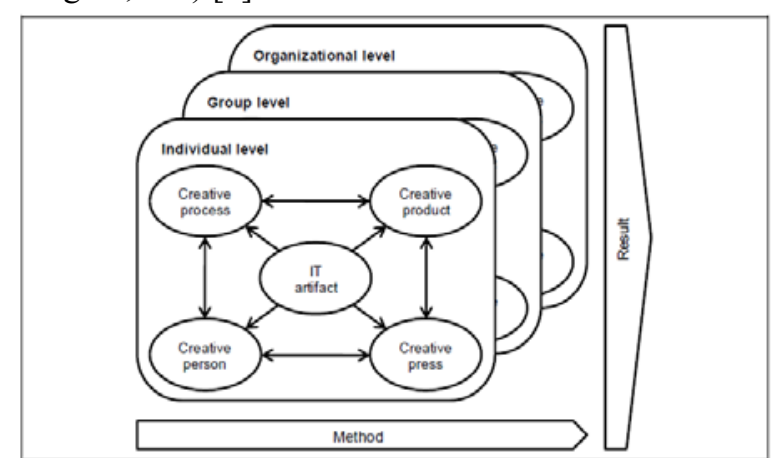

Fig. 1. Creativity Model 4-Ps

Couger J.D. states that the mentioned-above 4-Ps model provides a good structure for understanding creativity, as well as its application in the IS discipline.
The model's simplicity allows for the individual measurement and assessment of each component as well as the evaluation of the interaction of the components. In the present study, the 4-Ps model is applied in order to identify a study's focus perspectives on creativity. Though all four components have to be considered when taking in a holistic view on the phenomenon of creativity, research often considers only a subset of the model's elements. In order to determine this classification we characterize the paper's main constructs/concepts in terms of their relation to the process, the product, the person, or the press component of creativity [8].

The term "creativity" originates from the Latin word "creatio" - invention or development [10]. In the narrow sense the concept "creative input" is a processual factor of individual activities in creative and intellectual activities which result in innovative product development which did not exist before in the market of goods and services. Here we understand the "innovative product" not only as goods or services but also as new methods of research, conceptions, decision-making algorithms, etc. [12].

J. Perry and C. Shalley determine "creativity" as follows: "People can be creative in their activities due to generating new ways of doing their work, inventing new procedures or innovative ideas or due to application of known approaches under new conditions ..." [1], and such definition supposes achieving practical results and comprises all cognitive and personal qualities.

It is generally recognized that "creativity" is an indispensible and important part of human society development. Due to the productive, creative character of their activities people create new tools, new concepts of managing and system improvement, develop their abilities for unconventional thinking and making efficient decisions in the course of business. Due to the creative character of human activities, people were able to overcome their genotypically determined capabilities and accelerate scientific progress of modern society. "Creativity" is neither an exclusive prerogative of great minds, nor a part of certain areas of human activities and complexity of work. In other words the activity of modern society is manifested and continued in human creation, in investing creativity into productive activities, which become productive not only consumptive due to it.

Therefore, creativity is a personal trait which rests upon potential capabilities of every person in his/her need to be a unique individual.

Creativity can be considered as optimal development of all abilities of a personality, which is realized and manifested, in creative process.

We understand creativity as a combination of the following personal traits:

- creative thinking (an ability to find new solutions of problematic situations which can lead to new ideas and discoveries);

- originality (one's own view of a problem, imagination, sense of humor); 
- independence (an ability of establishing a goal, determining means of its achieving, an ability to defend one's point of view).

\section{Results and discussion}

The aim of creativity development is creating opportunities for students' self-realization during the process of training and further - during their own professional activities. The essence of the given process is in awakening natural forces of students from curiosity to self-actualization revealing itself in student's creative potential development and creative activity. Creativity is the base, the starting point for establishing creative potential of the future specialist.

The process of creativity development in higher educational institution will be successful if problemoriented approach is applied to training. The process of problem solving predetermines appearing of creative ideas and creative attitude of the students to their activities and communication which forms the basis of their creative potential and creativity in their further professional activities.

A problematic situation is a complex of certain conditions and circumstances characterized by some contradiction. A person finding himself or herself in the given situation realizes this contradiction as a need for obtaining new knowledge to deal with the contradiction.

M.L. Zueva notes in her research paper that the students who solve the problems found in study guides or problem books as a rule use the algorithm given by the teacher to do this. In practice this may lead to inability of the graduates to solve problems with modified conditions [5].

To form students abilities for solving problematic situations we need to apply problem-oriented approach to education. The main aim of problem-oriented approach is teaching students to work independently, form their research skills, develop their cognitive and creative abilities, creativity.

The ability to solve problems under current conditions is highly appreciated by the employers. If students acquire the ability to solve problems during their training process they will be in great demand. Besides, the ability to solve problems may be very useful throughout life in various situations.

To create a problematic situation we suggest application of case study method which supposes participation of both student and teacher in discussion of the problematic situation. As a rule, cases are prepared in the written form and they are based on real facts, are read, studied and discussed by students. The cases form the core of discussion in class guided by the teacher. That is why case study method includes both special type of study material and special ways of using this material in the educational process $[10$, p. 50].

The given method provides better opportunities for formation students' creative thinking as it supposes higher level of situation analysis and develops skills of both independent decision-making and independent choosing means and ways of solving the given problems. Case study is one of interactive methods of training based on the principles of students' interaction and activity, relying upon group experience and obligatory feedback. The environment formed for educational intercourse is characterized by openness, interaction of participants, equality of their arguments, accumulation of shared knowledge, opportunities of mutual estimation and control [4].

Case method supposes group and individual work. The teacher chooses a case, prepares, if necessary, a list of references required for finding the solution. The students who get the case discuss the situation, work out the solution, take the decision and prepare the written report either independently or together with their group guided by the teacher.

An important component of creativity development process when solving the cases is multivariance of solutions as opposed to one given stereotype of solution and established algorithm of solution.

When working on the case the student must:

- define the creative task and the problem of the given case;

- analyze the available information;

- compare the problem data to theoretical knowledge in the field of mathematics, be able to apply the given knowledge in a new situation, do mathematical modelling of the situation described in the case;

- suggest original ideas for the cases or new explanations when presenting the solution.

As a result of working at the case the student is involved into the following activities:

- generating the idea;

- development of solution for a new situation;

- application of divergent thinking (broad search for problem solution which can result in original creative solution);

- analysis, synthesis, comparison of various situations;

- solving problems and tasks which require finding regularities, properties, relations [2];

- associative thinking;

- imagination development;

- learn methods of creative thinking, which ensures obtaining, producing and accepting new (or subjectively new) knowledge [8].

The mentioned above qualities characterize a creative personality prepared for creative activities, being in-demand in all spheres of modern life.

Besides the cases, application of business roleplaying games will also encourage creativity development as the games are characterized by plenty of educational opportunities.

The game excites everybody - it stirs interest to the content, inspires with positive emotions, enhances mood.

During the business role-playing game the students may play various roles (those of company CEO, department manager, bookkeeper, accountant, etc.). It may happen that not all students will participate in the game. Then, these students may watch the process which allows them to perform evaluate, control analytical functions, noting how to apply the obtained 
knowledge in practice. In the process of watching the business role-playing game, the students form the positive image of their future profession and, accordingly, value attitude towards future professional activities.

It is possible to organize various games. Some games may involve all students. Other games may be designed for two players, then, all students get into pairs, play the situations and then results of each group are compared and discussed. The time of the game may also vary starting from 30 minutes to several classes.

The task of the teacher in organizing and guiding the game is as follows:

1. To choose the business role-playing game according to the studied subject.

2. To prepare, if necessary, the required materials for the game (cards, stocks, etc.).

3. To distribute the roles between the students and familiarize them with the game.

4. To make adjustments to the business role-plying game in the process of playing (time, additional conditions introduction, supervision of participants and lookers).

5. To sum-up. The teacher marks all positive and negative aspects, estimates every participant $[9, \mathrm{p}$. 404].

We think that this method of teaching encourages efficient development of student's creative abilities.

The players must not only take part in the game but also demonstrate such qualities as ability to team work, interpersonal communication skills, leader qualities, creativity in case of unforeseen extreme situation.

Besides, business role-playing game being an extremely dynamic process develops the skills of situation and feedback analysis, decision-making and long-term planning of activities. The students study eagerly when they are interested. This opportunity is provided by business role-playing games. During a business role-playing game the students may actualize their personal potential, It is recommended to use special equipment during the business role-playing game such as video recording which allows the participants taking a detached view when the game is over. It allows learning some interesting things about one's own behavior and about oneself.

\section{Conclusion}

Thus, "creativity" is an ability of a person to use knowledge, skills and abilities for creation of a product in a short time. A progressive way of development demands product creativity, as it is essential for further success of extension. F. Byron defined "creativity" as a product made by a creative person in the course of a creative process. He does not focus on creative environment in the definition. R.Woodman (1993) defines "creativity" as a creation of a valuable useful product when people work together in complex systems.

Thus, the meaning of the term "creativity» was extended from an individual level to a group level. Creative groups of people should be not uniform and not big. It is better if a head of creative group would have a democratic style of communication, so he/she could provide creative atmosphere for members of the group. Then productivity of creative group could increase as much as possible. Creativity is a driving force of economic and political development.

Thus, application of the problem-oriented approach and interactive methods in student training allows not only activation of their thinking but also forming the creative constituent, which is important for further professional activities and promoting solid career achievements.

\section{Acknowledgements}

The authors would like to thank National Research Tomsk Polytechnic University for the chance to participate in this useful, scientific and research forum.

\section{References}

1. J.E. Perry-Smith, C.E. Shelley, Academy of Management Review, 28, 89-106 (2003)

2. E. Politsinsky, L. Demenkova, O. Medvedeva, Procedia - Social and Behavioral Sciences, 206, 383-387 (2015)

3. M. Suzdalova, E. Politsinskaya, A. Sushko, Procedia - Social and Behavioral Sciences, 206, 394-398 (2015)

4. N.M. Borytko, Theory of education: study guide for the students of teacher training institutes (Volgograd: VGIPK RO publishers, 2006

5. M.L. Zueva, Efficiency of problematic approach application for key training competences formation / M.L. Zueva // Yaroslavl pedagogical review. 2007. - № 2 (51).-P. 36-47

6. Concept of creativity by J. Gillford and E.P. Torrance. BIBLIOTEKA.RU. URL Access mode: http://www.bibliotekar.ru/psihologia-2-1/142.htm

7. F. Barron, Journal of Abnormal and Social Psychology, 3 (51), 478 - 485 (1995)

8. J.D. Couger, L.F. Higgins, S. C. McIntyre, MIS Quarterly, (17)4, 375-397 (1993)

9. R.T. Brown, Creativity - What Are We to Measure? / in Glover, J.A., R.R. Ronning, C.R. Reynolds (eds.)

10. V.N. Petrova, Digital journal "Znaniye. Ponimaniye. Umeniye", 7, (2007)

11. E.V. Politsinskaya, Innovations in engineering: proceedings of international youth conference (Tomsk: TPU, 2012)

12. S.D. Polyakov, In search for pedagogic innovation (M.: Drofa, 2003)

13. S.L. Rubinstein, The principles of general psychology (SPb: "Piter" publishers, 2000)

14. A.V. Sushko, Russian economy in the XXI century: proceedings of XI International Scientific Practical Conference "Economic sciences and applied research into the fundamental problems of Russian economy modernization" devoted to 110th anniversary of economic education in Tomsk 
Polytechnic University (Tomsk,: TPU publishers, 2014)

15. Torrance MakKenna "Food of gods" / Digital resource - Access mode: URL: http://www.libok.net/writer/3995/kniga/18113/ma kkenna_terens/pischa_bogov/read/ 17

16. L.V. Chuprova, Proceedings of the conferences SRC Sotsiosfera, 41, 103-106 (2012) 